\title{
Myocardial fibrosis imaging based on T1- mapping and extracellular volume fraction (ECV) measurement in muscular dystrophy patients: proof of additional diagnostic value compared to conventional late gadolinium enhancement (LGE) imaging
}

\author{
Anca Florian', Anna Ludwig², Sabine Rösch², Handan Yildiz², Udo Sechtem², Ali Yilmaz ${ }^{1,2^{*}}$
}

From 17th Annual SCMR Scientific Sessions

New Orleans, LA, USA. 16-19 January 2014

\section{Background}

Cardiac involvement with progressive myocardial fibrosis leading to dilated cardiomyopathy is a major cause of death in muscular dystrophy patients. Extracellular volume fraction (ECV) measurement based on T1-mapping preand post-contrast promises the detection of early "diffuse" myocardial fibrosis that cannot be depicted by conventional contrast-imaging based on late gadolinium enhancement (LGE). With this study, we evaluated the presence of diffuse myocardial fibrosis in regions of "normal" (LGEnegative) and "diseased" (LGE-positive) appearing myocardium as well as its relation to the extent of left ventricular (LV) dysfunction and the occurrence of arrhythmias in Becker muscular dystrophy (BMD) patients.

\section{Methods}

Twenty-seven BMD patients $(35 \pm 12$ yrs $)$ and 28 matched healthy CONTROLS (33 \pm 8 yrs) underwent cardiovascular magnetic resonance (CMR) studies including ECV measurement and LGE-imaging. Ambulatory monitoring of arrhythmic events was performed by means of an external event loop recorder.

\section{Results}

Twenty BMD patients (74\%) demonstrated cardiac involvement as detected by typical inferolateral presence of LGE. Twelve patients (44\%) had an impaired LV ejection fraction - all being LGE-positive. Global myocardial ECV was significantly higher in the BMD group (29 \pm $6 \%)$ compared to the CONTROL group $(25 \pm 3 \%, \mathrm{p}=$ 0.005). Patients with cardiac involvement demonstrated higher global ECV $(31 \pm 6 \%)$ as well as significantly increased regional ECV not only in LGE-positive segments $(34 \pm 6 \%)$, but also in LGE-negative segments (28 $\pm 6 \%$ ) compared to BMD patients without cardiac involvement and to CONTROLS, respectively $(24 \pm 3 \%$ and $25 \pm 3 \%, \mathrm{p}=0.01)$. Global ECV in patients with cardiac involvement substantially correlated to LV ejection fraction $(r=-0.629, p=0.003)$ and to the number of LGE-positive segments $(\mathrm{r}=0.783, \mathrm{p}<0.001)$. On univariable analysis, global ECV - but not the categorical presence of LGE per se - was significantly associated with arrhythmic events (OR 1.97, CI 32.22-1.21, $\mathrm{p}=0.032$ ).

\section{Conclusions}

ECV measurement by CMR is a useful tool in assessing the total extent of myocardial fibrosis as well as in depicting subtle diffuse fibrosis in areas of normal appearing myocardium on LGE-images. Thus, myocardial ECV is a potential additional quantitative tool for accurate detection of cardiac involvement and risk stratification in muscular dystrophy patients.

${ }^{1}$ Cardiology and Angiology, University Hospital Münster, Münster, Germany Full list of author information is available at the end of the article 


\section{Funding}

This work was financially supported by a grant from the German Society of Cardiology (DGK; grant-ID DGK12/ yilmaz to A.Y.) and by the Robert-Bosch-Foundation (grant-ID KKF-11-14 to A.Y.).

\section{Authors' details}

${ }^{1}$ Cardiology and Angiology, University Hospital Münster, Münster, Germany.

${ }^{2}$ Cardiology, Robert-Bosch-Krankenhaus, Stuttgart, Germany.

Published: 16 January 2014

doi:10.1186/1532-429X-16-S1-P296

Cite this article as: Florian et al:: Myocardial fibrosis imaging based on T1-mapping and extracellular volume fraction (ECV) measurement in muscular dystrophy patients: proof of additional diagnostic value compared to conventional late gadolinium enhancement (LGE) imaging. Journal of Cardiovascular Magnetic Resonance 2014 16(Suppl 1): P296.

Submit your next manuscript to BioMed Central and take full advantage of:

- Convenient online submission

- Thorough peer review

- No space constraints or color figure charges

- Immediate publication on acceptance

- Inclusion in PubMed, CAS, Scopus and Google Scholar

- Research which is freely available for redistribution

Submit your manuscript at www.biomedcentral.com/submit
C Biomed Central 